\title{
The moon phases influence on the beginning of astronomical dawn determination in Yogyakarta
}

\author{
Abu Yazid Raisal ${ }^{1}$, Yudhiakto Pramudya ${ }^{1,2}$, Okimustava $^{2}$ and Muchlas ${ }^{1,2}$ \\ ${ }^{1}$ Program Studi Magister Pendidikan Fisika Universitas Ahmad Dahlan, Jalan Pramuka 42, \\ Sidikan, Umbulharjo, Yogyakarta 55161 \\ ${ }^{2}$ Pusat Studi Astronomi Universitas Ahmad Dahlan, Jalan Gondosuli 1 Yogyakarta
}

abuyazidraisal@gmail.com

\begin{abstract}
In astronomy, there are three types of dawn. They are astronomical, nautical, and civil dawn. The sunlight is starting to appear on the east horizon when the Sun altitude is $18^{\circ}$ below the horizon. Hence, there is a change on the sky brightness. The sky brightness can be affected by the moon phases. The sky brightness level is monitored by Sky Quality Meter (SQM). The SQM was installed upward to the zenith. There are 4 locations of measurement in Yogyakarta. The data has been collected for nine months to obtain the complete moon phases. The beginning of astronomical dawn is time when the sky brightness level is starting to decrease. The moving average algorithm was employed to determine the beginning of astronomical dawn. The time when the astronomical dawn begins is compared with the sun altitude calculation. The sun altitude calculation has been done using accurate times software. The difference of the beginning of astronomical dawn by measurement and calculation are $18.61 \pm 6.81$ minutes, $19.12 \pm 3.28$ minutes, $31.12 \pm 7.76$ minutes, and $27.24 \pm 8.04$ minutes, on the new moon (0), on the first quarter (0.25), on the full moon (0.5) and on the last quarter $(0.75)$, respectively. The weather condition is also contributing to the results.
\end{abstract}

Keyword : astronomical dawn, moon phases, sky brightness, Sky Quality Meter

\section{Introduction}

The dawn in astronomy is divided into three types. They are depends on the height of the sun below the horizon. The types of dawn are the astronomical dawn, the nautical dawn and the civil dawn. The astronomical dawn, the nautical dawn and the civil dawn are the types of dawn when the sun's heights are 18 degrees to 12 degrees, 12 degrees to 6 degrees and 6 degrees to 0 degree below the horizon, respectively. The definition is composed by United Stated Naval Observatory Astronomical Application Department [1]. Each type of the dawn has specific sky brightness. In Islam, the study of the sky brightness is important to determine the prayer time especially when the sun is below the horizon. for example, the fajr prayer time is related to the dawn or morning twilight [2].

The level of sky brightness can be quantified by using the Sky Quality Meter (SQM). Hence, the brightness of the sky can be measured objectively. SQM can also be used to measure the level of light pollution in a particular place [3][4]. SQM can also be used to determine the first contact of the total solar eclipse [5]. SQM is a relatively low-cost 
simple photometer, lightweight, pocket-sized and with an error rate of less than 3\% [6]. Sky Quality Meter (SQM) is a device that can be used to measure the illumination of the night sky as seen in figure 1. The illumination measured in mag/arcsec2. The spectral response range of SQM is wide enough, i.e. visual range $400-650 \mathrm{~nm}$ with peaks of about $540 \mathrm{~nm}$. Hence, it is suitable with spectral sensitivity of the human eye [6].

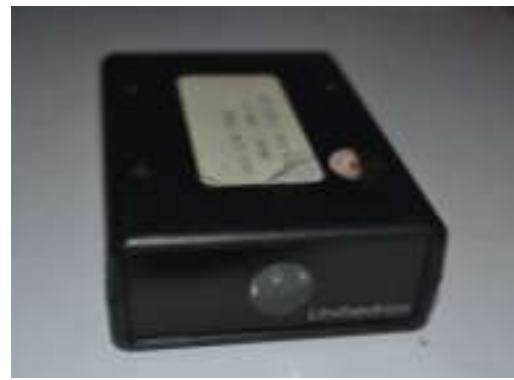

Figure 1. The front view of SQM

The sky brightness level data that is measured by SQM reflect changes of the sky brightness as the time changes. This time are related to the sun height below the horizon the sky brightness [7] as shown in figure 2. The figure shows the dusk condition. The dawn condition is similar to that figure only the name of the dusk is change to the dawn. We can see that the value of sky brightness level is leveled off in the end of the astronomical dusk and the beginning of the astronomical dawn.

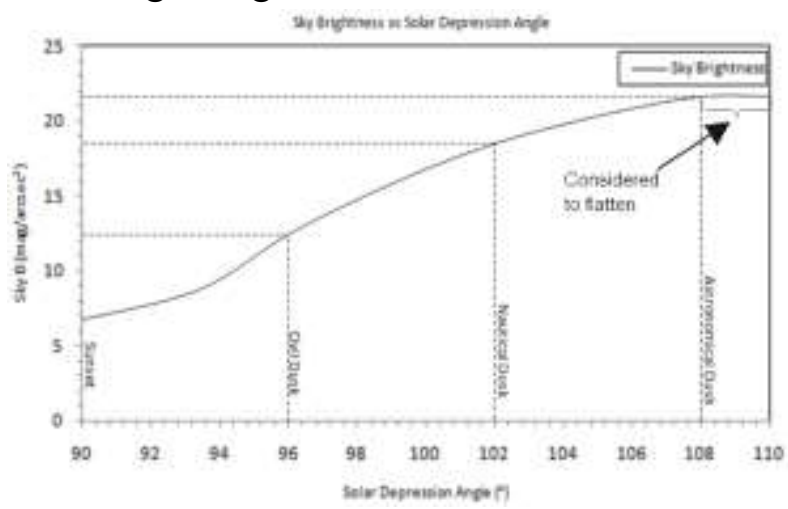

Figure 2. The sky brightness as a function solar depression angle [7]

There are several factors that can modify the sky brightness level. They are the integrated light from distant galaxy, the integrated starlight within our galaxy, the zodiacal light, the night airglow, the aurora, the twilight emission light, natural and artificial light pollution, weather and the moon phases [8][9].

The light pollution condition is different between big city and small city. Yogyakarta is populous small city. It has area of $32.5 \mathrm{~km}^{2}$ and population density of $12,669 \mathrm{per} \mathrm{km}^{2}$. The city has a numerous tourism objects. Hence, the light pollution is high. As a comparison with Gunung Kidul that is located in the same province as Yogyakarta. Gunung Kidul has a large area which is $1,485.36 \mathrm{~km}^{2}$. The population density is $482 \mathrm{per}$ $\mathrm{km}^{2}$. The light pollution at this area is low [11].

The moon is not always visible even at night. The moon appearance is not always a full circle. At a particular time, the Moon looks just like a thin arch. The moon surface reflects the sun rays. The part of the moon that gets the rays and faces the earth causes 
the Moon to have some form of sighting called the moon phase. They are new moon, first quarter, full moon and last quarter. The moon phase is a phase calculated based on what part of the moon gets sunlight when viewed from the earth. This Moon phases affect the brightness of the sky.

The phase values range from 0 to 1 . The phase of 0 is the phase at which the new moon begins whereas phase 0.5 is the phase at which the full moon occurs. After the full moon phase, the phase value will be close to 1 but never equal to 1 . The value of the moon phase is shown table 1 [10]. The moon phases repeat every 29.5 days. This period is called the synodic period.

Table 1. The value of the moon phase

\begin{tabular}{cc}
\hline Value & Moon phase \\
\hline 0 & New moon \\
0.25 & First quarter \\
0.5 & Full moon \\
0.75 & Last quarter \\
\hline
\end{tabular}

This research will be focused on the investigation of the influence of the moon phases to the sky brightness level. The sky brightness level data that is measured by using SQM will be used to determine the astronomical dawn time.

\section{Methodology}

Data acquisition is performed in different locations with a span from May 2016 to January 2017. This research use the instruments i.e. Sky Quality Meter-LU, computer and several software. The software are Microsoft Excel, Unihedron Device Manager (UHD) and Accurate Times.

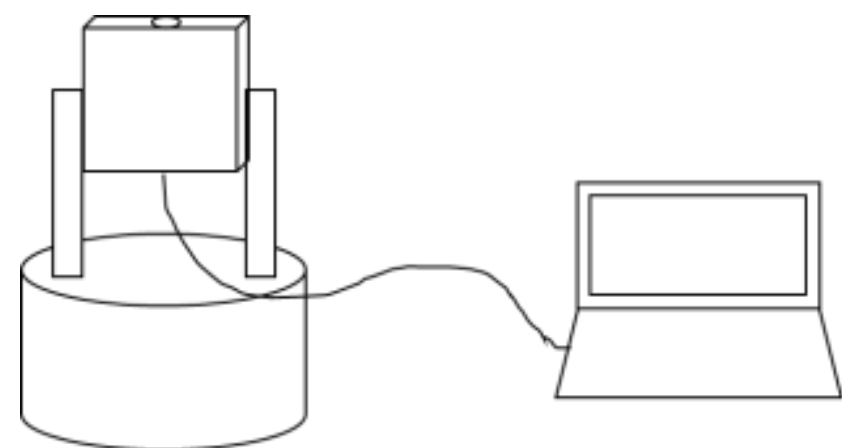

Figure 3. The scheme of SQM installation and connection to the computer

SQM was installed facing to the zenith. It is connected to computer with a USB cable as shown in figure 3. The sky brightness level data was captured every 5 seconds from around 3 am to 6 am local time. This research was conducted in several places shown in table 2. The location A, B and C are located in Yogyakarta. The location D is located in Gunung Kidul. 
Table 1. Location of installed SQM

\begin{tabular}{ccc}
\hline Location & Latitude & Longitude \\
\hline A & $7^{\circ} 47^{\prime} 55.4{ }^{\prime \prime} \mathrm{S}$ & $110^{\circ} 23^{\prime} 2.4^{\prime \prime} \mathrm{E}$ \\
$\mathrm{B}$ & $7^{\circ} 48^{\prime} 39.3^{\prime} \mathrm{S}$ & $110^{\circ} 23^{\prime} 24.5^{\prime \prime} \mathrm{E}$ \\
$\mathrm{C}$ & $7^{\circ} 50^{\prime} 5.2^{\prime \prime} \mathrm{S}$ & $110^{\circ} 23^{\prime} 0.44^{\prime \prime} \mathrm{E}$ \\
$\mathrm{D}$ & $8^{\circ} 8^{\prime} 17^{\prime \prime} \mathrm{S}$ & $110^{\circ} 34^{\prime} 40^{\prime \prime} \mathrm{E}$ \\
\hline
\end{tabular}

The sky brightness level data was analyzed using Microsoft Excel by utilizing the moving average tool. The steps to analyze the data were:

1) Calculating the difference between the sky brightness level of current measurement and previous measurement time. Hence, we would have data set of the sky brightness level differences.

2) Choosing the data analysis menu in Microsoft Excel to obtain the moving average value for the data set. The interval that to be used was six data points. The moving average method utilization was intended to obtain smooth variation in data [12].

3) Finding the zeroes of the data that was obtained on the step 2.

4) Choosing the zero that is located before negative value of moving average.

5) Finding the time correspond to the zero on the step 4. It is beginning of astronomical dawn based on measurements $\left(t_{\text {measure }}\right)$.

The time when the sun altitude is $18^{\circ}$ degrees below the horizon can be calculated by Accurate Times software. It is called as $\left(t_{\text {count }}\right)$. The difference in the beginning of astronomical dawn time can be calculated by equation 1 .

$$
\Delta t=t_{\text {measure }}-t_{\text {count }}
$$

The $\Delta t$ is called times difference.

\section{Results and Discussion}

The SQM profile on the moon phase of 0.5 shown in figure 4. Data obtained at location A on May $20^{\text {th }}, 2016$ and December $13^{\text {th }}, 2016$. The dotted lines are the $t_{\text {count }}$. At $t_{\text {count }}$, the sky brightness level were relatively constant. The thick lines show $t_{\text {measure }}$. At $t_{\text {measure }}$ , the sky brightness level start to decline gradually. This is due to the Sun rays began to irradiate layer of Earth's atmosphere. The times difference on those days are 18.51 minutes and 35.79 minutes. Figure 4 also shows there is noise at graph on December $13^{\text {th }}$. This is due to the weather conditions. It was cloudy day. Hence, it is difficult to $t_{\text {measure }}$. 


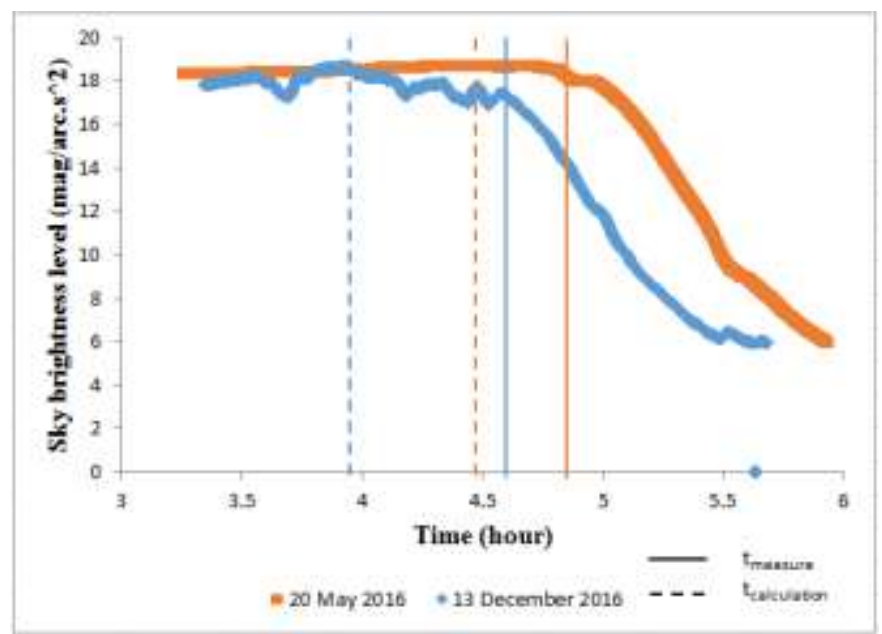

Figure 4. The SQM profile on the moon phase of 0.5

The SQM profile on the moon phase of 0.75 is shown in figure 5. Data obtained at location B on June $27^{\text {th }}, 2016$ and at location D on October $23^{\text {rd }}, 2016$. The time differences on those days are 37.90 minutes and 21.84 minutes. The time differences at location $\mathrm{D}$ is smaller than location $\mathrm{B}$. the sky brightness level at location $\mathrm{D}$ is higher than location B. This is because the location B is located in the many urban light pollution. The location of $\mathrm{D}$ is located in a coastal area and have low light pollution. Figure 5 also shows that there are noises on June $27^{\text {th }}$. This condition is also due to the cloud.

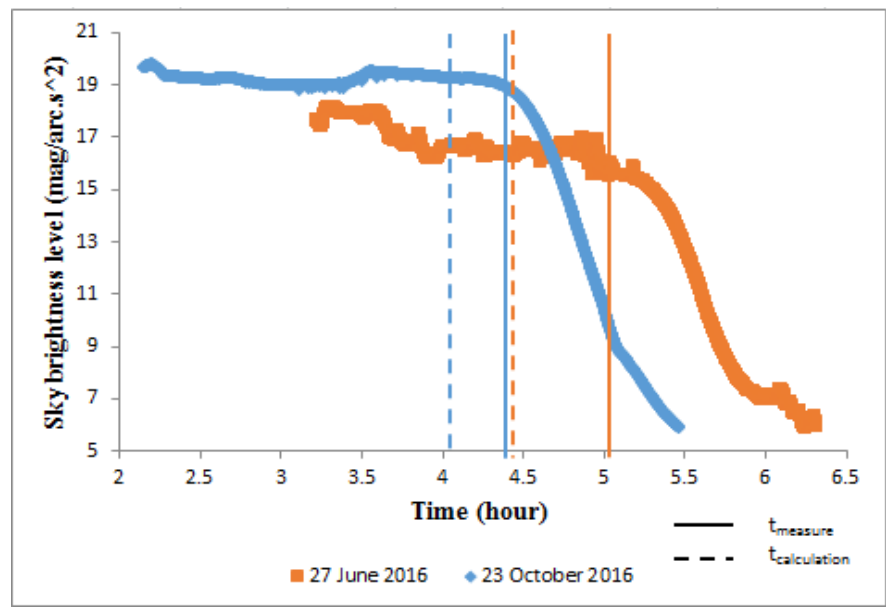

Figure 5. The SQM profile on the moon phase of 0.75

The distribution of time differences for entire moon phases is shown in figure 6 . The time differences between 8 to 38 minutes. It reaches the maximum value when it is around the full moon phase (0.5). On the first quarter phase $(0.25)$, the moon already set when collecting data. Whereas on the last quarter phase (0.75), moon began to rises when collecting data. These condition generate time differences on the last quarter larger than on the first quarter. The time differences of the beginning of astronomical dawn are $18.61 \pm 6.81$ minutes, $19.12 \pm 3.28$ minutes, $31.12 \pm 7.76$ minutes, and $27.24 \pm 8.04$ minutes, on the new moon (0), on the first quarter $(0.25)$, on the full moon $(0.5)$ and on the last quarter $(0.75)$, respectively. 


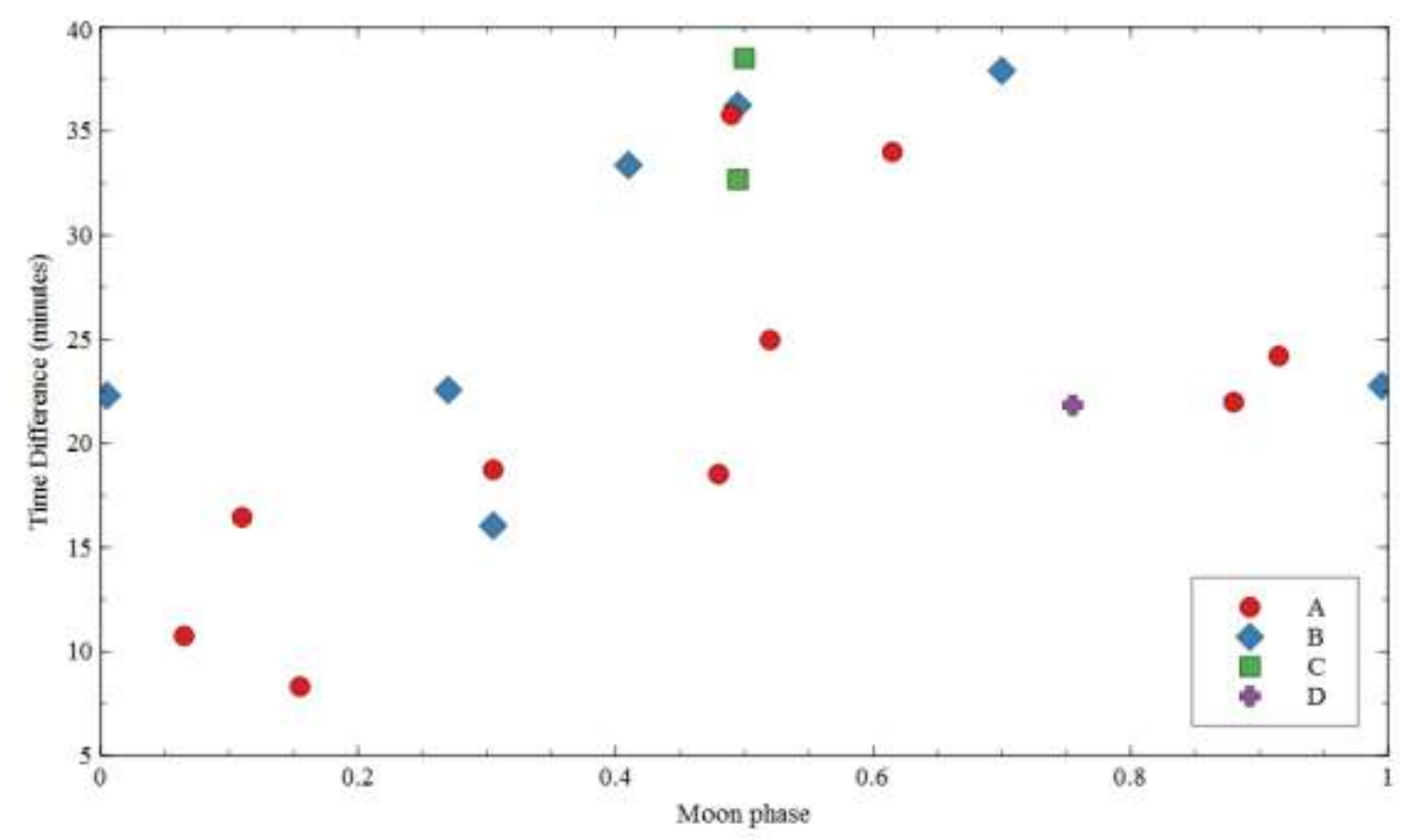

Figure 6. The distributions of times difference for entire moon phase

\section{Conclusion}

The difference of the beginning of astronomical dawn by measurement and calculation are 18.61 \pm 6.81 minutes, $19.12 \pm 3.28$ minutes, $31.12 \pm 7.76$ minutes, and $27.24 \pm 8.04$ minutes, on the new moon (0), on the first quarter $(0.25)$, on the full moon $(0.5)$ and on the last quarter (0.75), respectively. The weather condition is also contributing to the results. The moon phases affect the beginning of astronomical dawn. The darker the sky then the sky brightness level will be higher and vice versa.

\section{Acknowledgements}

This research was supported by the research funding from Lembaga Penelitian dan Pengembangan Universitas Ahmad Dahlan.

\section{References}

[1] Herdiwijaya D 2016 Sky Brightness and Twilight Measurement at Jogjakarta City, Indonesia Journal of Physics: Conference Series 7712

[2] Nor S A M and Zainuddin M Z 2012 Sky Brightness for Determination of Fajr and Isha Prayer by Using Sky Quality Meter International Journal of Scientific \& Engineering Research 31

[3] Pun C S J, Chu W S and Chung F T W 2012 The Night Sky Monitoring Network in Hongkong. Highlights of Astronomy 16740

[4] Hideaki S 2013 Research on Light Pollution by Using a Sky Quality Meter Young Scientists Journal 23

[5] Pramudya Y and Arkanuddin M 2016 The Sky Brightness Measurement During the 2016 Solar Eclipse in Ternate Journal of Physics: Conference Series 7711 
[6] Herdiwijaya D and Arumaningtyas E P 2011 Pengukuran Kecerlangan Langit Arah Zenit di Bandung dan Cimahi Menggunakan Sky Quality Meter Prosiding Seminar Himpunan Astronomi Indonesia 6

[7] Niri M A, ZAinuddin M Z, Man S, Nawawi M S A M, Wahab R A, Ismail K, Zaki N H A, Ghani A A and Lokman M A A 2012 Astronomical Determinations for the Beginning Prayer Time of Isha' Middle-East Journal of Scientific Research 12104

[8] Hassan A H, Abdel-Hadi Y A, Issa I A and Hassanin N Y 2014 Naked eye observations for morning twilight at different sites in Egypt NRIAG Journal of Astronomy and Geophysics 323

[9] Yao S, Zhang H T, Yuan H L, Zhao Y H, Dong Y Q, Bai Z R, Deng L C and Lei Y J 2013 Moon Night Sky Brightness Simulation for the Xinlong Station Research in Astronomy and Astrophyics 131255

[10] Kamshory and Syafii 2014 Simulator Posisi Matahari dan Bulan Berbasis Web dengan WEBGL Jurnal Nasional Teknik Elektro 3185

[11] https://yogyakarta.bps.go.id.

[12] Mitra S K 2011 Usefulness of Moving Average Based Trading Rules in India International Journal of Business and Management 6200 